\title{
Study of the Antibacterial Properties of a Composition Based on Chitosan Obtained from Dead Bees Apis Mellifera
}

\author{
Khaydarova Kh. A. \\ Bukhara State University, Uzbekistan \\ Nurutdinova F. M. \\ Bukhara State University, Uzbekistan
}

Ikhtiyarova G. A.

Tashkent State Technical University, Uzbekistan

Corresponding author email: axtam-xaydarov@mail.ru

Khaydarov A. A.

Bukhara Institute of Engineering and Technology, Uzbekistan

\begin{abstract}
The article provides data on the development of a new thickening composition for printing cotton-lye fabric with antibacterial properties based on biodegradable polymers Chitosan synthesized from Apis Mellifera bee dead with CMC with addition of CMC and synthetic hydrolyzed acrylic emulsion. Studied the fungicidal properties of the developed mixed thickener for active dyes used in printing fabrics. As a result of observations, it was revealed that these new thickeners on the basis of exhibit pronounced antimicrobial activity in relation to the micelle fungus Aspergillus terreus. The optical density of the samples shows that these thickeners are resistant to mycelial fungi. Among thickeners, thickeners based on Uzhitan-?MS-HAE, Uzkhitan-CMS have the most pronounced bactericidal activity, and these thickeners are more stable, they can be used the next day and even on the second day for printing mixed fabrics.
\end{abstract}

Keywords---biopolymer, chitin, chitosan, dead bees, fungicide, thickener

\section{Introduction}

The biodegradable aminopolysaccharide chitosan, which is a promising biomaterial in various branches of the textile, food industry, medicine, and is also widely used in the synthesis of new natural compounds, occupies an increasingly prominent place in the world among the important scientific directions of rapidly emerging in the field of natural polymers (Galbraykh, 2001). The consumption of natural polymers in the textile industry today reaches more than half of their total production. Therefore, one of the urgent problems is a comprehensive study of biopolymers in order to create new properties that meet the requirements of the time (Ikhtiyarova et al., 2018).

In our country, certain results have been achieved in the chemical industry, in particular, large-scale practical measures have been taken to provide the local market with import-substituting chemical reagents. It should be noted that the Republic of Uzbekistan pays great attention to measures for the system of scientifically based introduction of industrial facilities and environmental protection through the introduction of innovative technologies. The Action Strategy for the further development of the Republic of Uzbekistan outlines tasks for "Improving the industry to a qualitatively new level, further intensifying the production of finished products on the basis of deep processing of local raw materials, mastering the production of fundamentally new types of products and technologies."In this regard, in the republic, the production of chitin and chitosan from local raw materials and the study of their physical 
and chemical properties, their use as a thickener for stuffing cotton-silk blended fabrics is of great importance in the textile industry (Shahidi et al., 1999; Abdou et al., 2008).

In the textile industry, starch and its derivatives are used for sizing Mardonov et al. (2019), finishing and for printing cotton and mixed fabrics based on them as thickening agents (Ikhtiyarova et al., 2018; Khaydarova et al., 2019). At the same time, starch is a rich medium for obtaining energy by many microorganisms through fermentation processes. Fermentation is the process of breaking down organic substances, mainly carbohydrates, under the influence of microorganisms or enzymes isolated from them, without the participation or with the participation of oxygen. In this regard, preservatives (antimicrobial agents) are often used in the textile industry, which are able to prevent liquefaction of ready-made thickeners (prepared for future use with a view to several days). An alternative to the use of preservatives is the modification of starch thickeners or the addition of chitosan. They must be inert with respect to the action of microorganisms entering solutions from the environment. In this case, it is expected that the shelf life of the prepared thickener increases many times, which is economically beneficial, increases the environmental safety of technological processes, simplifies the technological process and leads to a decrease in energy consumption (Feng et al., 2019; Bano et al., 2017).

In this regard, we have developed a new composition of thickening compositions for printing cotton-lye fabric with antibacterial properties based on biodegradable polymers Chitosan synthesized from ApisMellifera dead bees with CMC with the addition of CMC and hydrolyzed acrylic emulsion. The composition of the thickener is shown in the table. The ingredients used in the finishing factories of the textile industry must have antibacterial properties, otherwise they are unusable after 24 hours. Recently, the use of thickeners with biocidal properties has been considered as a promising method of tissue bioprotection from the effects of molds. We have studied the fungicidal properties of a developed mixed thickener for active dyes used in printing fabrics.

Table 1

Composition of printing inks

\begin{tabular}{llll}
\hline \multicolumn{1}{c}{ Ingredients, g / kg } & $\mathrm{A}$ & $\mathrm{B}$ & $\mathrm{C}$ \\
\hline Activedye & 3 & 3 & 3 \\
DGT thickener & 30 & - & - \\
Carboxymethylstarch (CMC) & - & 60 & 30 \\
Chitosan & - & - & 0,5 \\
CMC & - & - & 19,5 \\
GAE & - & - & 10 \\
Urea & 150 & 150 & 50 \\
Ludigol & 10 & 10 & - \\
Sodium & 15 & 15 & 10 \\
Water & 792 & 762 & 872 \\
Total: & 1000 & 1000 & 1000 \\
\hline
\end{tabular}

We used Czapek-Dox's elective medium containing 6-ball wort, which is a rich substrate for filamentous fungiChemical composition of the nutrient medium Czapek-Doxa (g / l): glucose-30.0; $\mathrm{NaNO}_{3}-3.0 ; \mathrm{K}_{2} \mathrm{HPO}_{4}-1.0$; $\mathrm{MgSO}_{4} \times 7 \mathrm{H}_{2} \mathrm{O}-0.5 ; \mathrm{KCl}-0.5 ; \mathrm{FeSO}_{4} \times 7 \mathrm{H}_{2} \mathrm{O}-0.01$; agar-agar 25; distilled water - pH 6-6.5. The medium was sterilized at 1.0 ATM. For cultivation, a cellulolytic active strain of pure cultures of the fungus Aspergillusterreus was used, obtained from the culture collections of the Institute of Microbiology of the Academy of Sciences of the Republic of Uzbekistan. The medium with the inoculated samples, the thickener, was incubated in a thermostat at 28 ${ }^{\circ} \mathrm{C}$ for 5 days. Determination of the fungicidal activity was carried out in vitro (Adler, 1992). Freshly prepared thickeners were introduced into the medium under aseptic conditions in an amount of 1: 2. Optical density was measured in a spectrophotometer at $550 \mathrm{~nm}$. As a result of observations, it was revealed that new thickeners on the basis exhibit pronounced antimicrobial activity against the micellar fungus Aspergillusterreus. The absorbance of the samples shows that these thickeners are resistant to filamentous fungi (Bégin \& Van Calsteren, 1999; Ahmed \& Ikram, 2016).

The optical density of the thickener is little changed by the influence of the fungus Aspergillusterreus. This indicates that the constituent parts of the developed thickener are not a good substrate for microorganisms (Widyaningrum et al., 2020; Cevallos et al., 2019). The figure shows that on the 3rd day of cultivation, on the surface of the thickener 4 (control) of the Czapek-Dox medium, the formation of a massive film was observed, which is a characteristic sign of the growth of microorganisms. At the same time, thickening-1 Uzkhitan-KMK-GAE, thickening-2 Uzkhitan-KMK, thickening-3 Uzkhitan-GAE remained practically transparent, which is also shown in 
Figure 1. The picture shows that the new mixed thickener is highly resistant to bacteria and exhibits fungicidal properties. Among thickeners, thickeners based on Uzhitan-KMK-GAE, Uzhitan-KMK have the most pronounced bactericidal activity, and these thickeners are more stable, they can be used the next day and even on the second day for printing mixed fabrics.

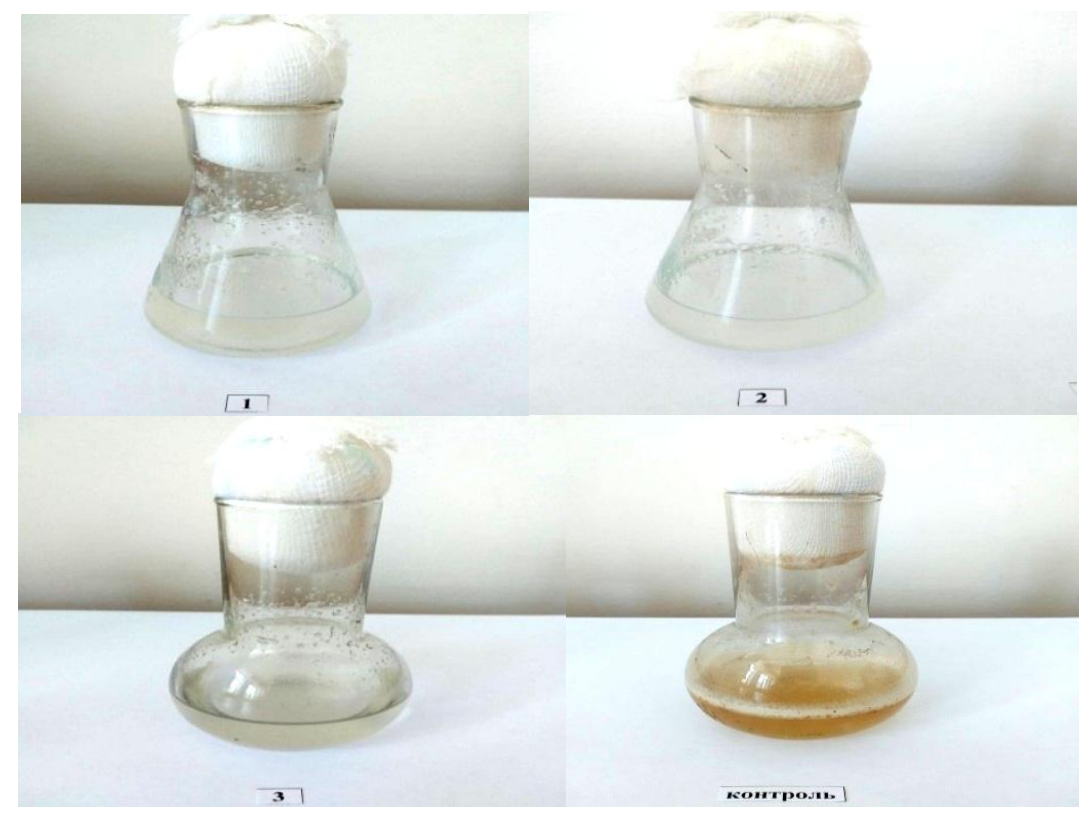

Figure 1. Thickeners and Czapek-Dox medium, cultivation of Aspergillusterreus after 5 days

Based on the above, it can be concluded that the first developed thickening water-soluble polymer compositions with desired properties based on a synergistic polymer system consisting of carboxymethyl starch and chitosan, a hydrolyzed acrylic emulsion can be used instead of expensive imported ingredients. Revealed bactericidal properties of mixed thickeners based on carboxymethylated starch and water-soluble polyacrylates (Sobisch \& Lerche, 2008; White et al., 2003). They exhibit pronounced antimicrobial activity against various types of microorganisms that cause damage to the thickener. This mixed thickener is stable and can be used even on the second day for printing mixed fabrics with reactive dyes. Thus, chitosan has valuable properties that can improve the antimicrobial properties of finished textile materials and makes it a promising textile auxiliary substance in the textile industry. Due to its biological activity, chitosan imparts fungicidal and bacteriostatic properties to textile materials, and increases the durability of textiles (Nakano et al., 1994; Ma \& Michailides, 2005).

\section{References}

Abdou, E. S., Nagy, K. S., \& Elsabee, M. Z. (2008). Extraction and characterization of chitin and chitosan from local sources. Bioresource technology, 99(5), 1359-1367. https://doi.org/10.1016/j.biortech.2007.01.051

Adler, R. V. (1992). Antimikrobe properties with antiseptic. J. Chem. Teech. Biotechnol, (30), 259.

Ahmed, S., \& Ikram, S. (2016). Chitosan based scaffolds and their applications in wound healing. Achievements in the life sciences, 10(1), 27-37. https://doi.org/10.1016/j.als.2016.04.001

Bano, I., Arshad, M., Yasin, T., Ghauri, M. A., \& Younus, M. (2017). Chitosan: A potential biopolymer for wound management. International journal of biological macromolecules, 102, 380-383. https://doi.org/10.1016/j.ijbiomac.2017.04.047

Bégin, A., \& Van Calsteren, M. R. (1999). Antimicrobial films produced from chitosan. International Journal of Biological Macromolecules, 26(1), 63-67. https://doi.org/10.1016/S0141-8130(99)00064-1

Cevallos, M. A. S., Rosado, C. A. Z., \& Terán, O. V. T. (2019). The procedure used on diagnostic evaluation process. International Journal of Health \& Medical Sciences, 3(1), 1-10. https://doi.org/10.31295/ijhms.v3n1.98

Feng, P., He, J., Peng, S., Gao, C., Zhao, Z., Xiong, S., \& Shuai, C. (2019). Characterizations and interfacial reinforcement mechanisms of multicomponent biopolymer based scaffold. Materials Science and Engineering: C, 100, 809-825. https://doi.org/10.1016/j.msec.2019.03.030

Galbraykh, L. S. (2001). Hitin and chitosan: building, properties, application/HpGalbraykh//Sorovsky educational magazine. - T. 7, No. 1. Page 51-56. 
Ikhtiyarova G. A., Khurbonaliyeva Z. A., \& Khaydarova Kh. A. (2018). Application and extraction chitin and chitosan from dead honey beesRepublican scientific journal. Bulletin of the South Kazakhstan Medical Academy VOL.I № 4(84). pp. 27-29.

Ikhtiyarova G.A., Mamatova Sh.B., Kurbanova F.N. (2018) Receiving and characterization of chitin and chitosan from a bee of Apismellifera. /Universum magazine. 5 (50).

Ikhtiyarova G.A., Nuritdinova F.M., Muinova N.B./ A new promising method for obtaining chitin, chitosan from dead bees and its application. International conference "Contemporary Problems of Polymer Science". Tashkent. pp. 77-80.

Khaydarova, H. A., Ikhtiyarova, G. A., \& Khaydarov, A. A. (2019). Method Of Obtaining A Chitosan Aminopolysaccharide From Behbat Apis Millifera. Chemical Journal of Kazakhstan.

Ma, Z., \& Michailides, T. J. (2005). Advances in understanding molecular mechanisms of fungicide resistance and molecular detection of resistant genotypes in phytopathogenic fungi. Crop Protection, 24(10), 853-863. https://doi.org/10.1016/j.cropro.2005.01.011

Mardonov S. E., Norova M. S., \& Khaidarov A. A. (2019), Structural and mechanical properties of new sizing preparations based on uzkhitan and synthetic acrylic polymer. Scientific and technical journal of Namangan Engineering and Technical Institute, Namangan, №5, p. 115.

Nakano, H., Kizaki, H., \& Sakaguchi, G. (1994). Multiplication of Clostridium botulinum in dead honey-bees and bee pupae, a likely source of heavy contamination of honey. International journal of food microbiology, 21(3), 247-252. https://doi.org/10.1016/0168-1605(94)90031-0

Shahidi, F., Arachchi, J. K. V., \& Jeon, Y. J. (1999). Food applications of chitin and chitosans. Trends in food science \& technology, 10(2), 37-51. https://doi.org/10.1016/S0924-2244(99)00017-5

Sobisch, T., \& Lerche, D. (2008). Thickener performance traced by multisample analytical centrifugation. Colloids and Surfaces A: Physicochemical and Engineering Aspects, 331(1-2), 114-118. https://doi.org/10.1016/j.colsurfa.2008.05.040

White, R. B., Sutalo, I. D., \& Nguyen, T. (2003). Fluid flow in thickener feedwell models. Minerals Engineering, 16(2), 145-150. https://doi.org/10.1016/S0892-6875(02)00252-2

Widyaningrum , I. ., Wibisono, N. ., \& Kusumawati, A. H. . (2020). Effect of extraction method on antimicrobial activity against staphylococcus aureus of tapak liman (elephantopus scaber 1.) leaves. International Journal of Health \& Medical Sciences, 3(1), 105-110. https://doi.org/10.31295/ijhms.v3n1.181 